\title{
Cot deaths in Edinburgh: infant feeding and socioeconomic factors
}

\author{
J. K. MASON
}

From the Department of Forensic Medicine, University of Edinburgh

\section{R. A. HARKNESS}

Lately from the Department of Clinical Chemistry, University of Edinburgh, and the Royal Hospital for Sick Children, Edinburgh

\author{
R. A. ELTON \\ From the Medical Computing and Statistics Unit, University of Edinburgh
}

\author{
SHEILA BARTHOLOMEW \\ From the Department of Pathology, Royal Hospital for Sick Children, Edinburgh
}

SUMMARY One hundred and twenty-six consecutive cases of sudden infant death syndrome (SIDS) in the Edinburgh area have been studied with particular reference to the interrelationship of feeding, associated biochemical changes, and social status. There was an excess of cases born to parents in Social Classes IV and V: the effect was maximal in children who died beyond 12 weeks of age. A low-grade uraemia was discovered in approximately one-fifth of the cases; analysis showed this to be related most strongly to bottle-feeding. Feeding habits were found to be associated with social class and this accounted for the relationship between bottle-feeding and the youth of mothers and also for an apparent relationship between uraemia in the infant and social class of the mother. Mothers of SIDS children were younger than expected and SIDS was found to be more likely with second children than with first. There was no evidence that severe electrolyte imbalance is common in SIDS cases, nor did the findings support the suggestion that cross-infection due to overcrowding is an important aetiological factor. The significant factors of young motherhood, low social status, bottle-feeding, and mild uraemia in the babies are interrelated and seem to focus attention on unwitting 'mothering problems'. It is, however, not easy to see how this, or any other hypothesis, can account for all cases of SIDS.

In the search for conditions predisposing to cot deaths or the sudden infant death syndrome (SIDS), those which are most frequently described include low socioeconomic status ${ }^{1-4}$ and non-breast-feeding with particular emphasis on the composition of the artificial food. ${ }^{56}$ Attention has been drawn increasingly in recent years to the importance of suboptimal mother care in the aetiology of the condition. ${ }^{78}$ It is possible that these factors are interrelated and that any significance attached to each one individually is unjustified. The main purpose of this paper is to examine this proposition in the light of experience gained in Edinburgh.

\section{Materials and methods}

Since 1974 it has been possible, through the collaboration of Procurators Fiscal, for all post-mortem dissections on supposed cases of SIDS in Edinburgh to be concentrated at the Royal Hospital for Sick Children. The dissections have been undertaken by a forensic or a paediatric pathologist; frequently they have acted together. The necropsy has been augmented routinely by microbiological, cytological, and biochemical investigations; inevitably some tests have been omitted from a number of cases. After the event, the mothers have 
been interviewed by a single home visitor; visiting was, however, only on an ad hoc basis when the study began and some background data are not available for many of the early cases.

This paper relates to 126 consecutive cases examined for Procurators Fiscal. It is emphasised that we have worked to the purely clinical definition of cot deaths put forward by Adelson and Kinney'- 'the death of a child (in its sleep) who was thought to be in good health or whose terminal illness appeared to be so mild that the possibility of a fatal outcome was not anticipated'. We have deliberately not insisted on the pathological addendum 'and in whom a thorough post-mortem examination failed to demonstrate an adequate cause of death'10 - firstly, because this introduces the variable of observer credulity; secondly, because it has been shown that there are few, if any, characteristics which distinguish the so called explained from the unexplained cot deaths ${ }^{411}$; and, thirdly, because it is the manner of dying which poses the major sociological problem. The basic criterion for selection has been - was the death reportable to the Procurator Fiscal?

Seventy-six cases came from within the District of the City of Edinburgh; 50 were sent in from the generally less congested surrounding districts. The catchment from the latter is certainly not as complete as from the city and no valid conclusions have been drawn about the relative distribution between the two areas; except where otherwise stated, we have made no distinction between the two groups.

\section{Results}

BIOCHEMICAL

We have aimed in each case to estimate the sodium, potassium, and urea concentrations in the vitreous humour of the eye - the electrolytes by flame photometry and the urea by a standard sensitive colorimetric method. The results are shown in Figs. 1, 2 , and 3 .

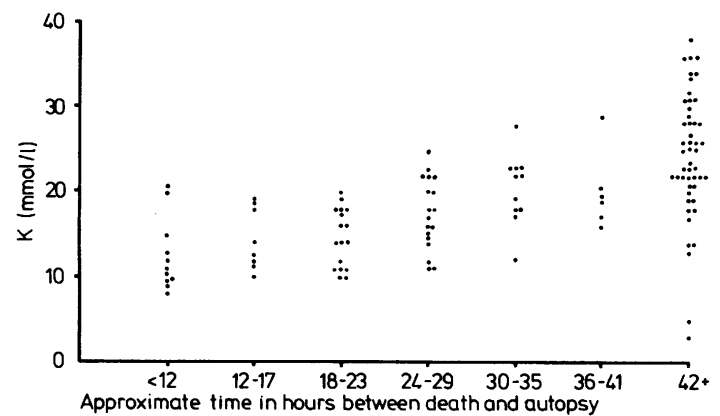

Fig. 1 Potassium concentration in the vitreous humour of 120 SIDS cases related to the interval between death and post-mortem dissection.

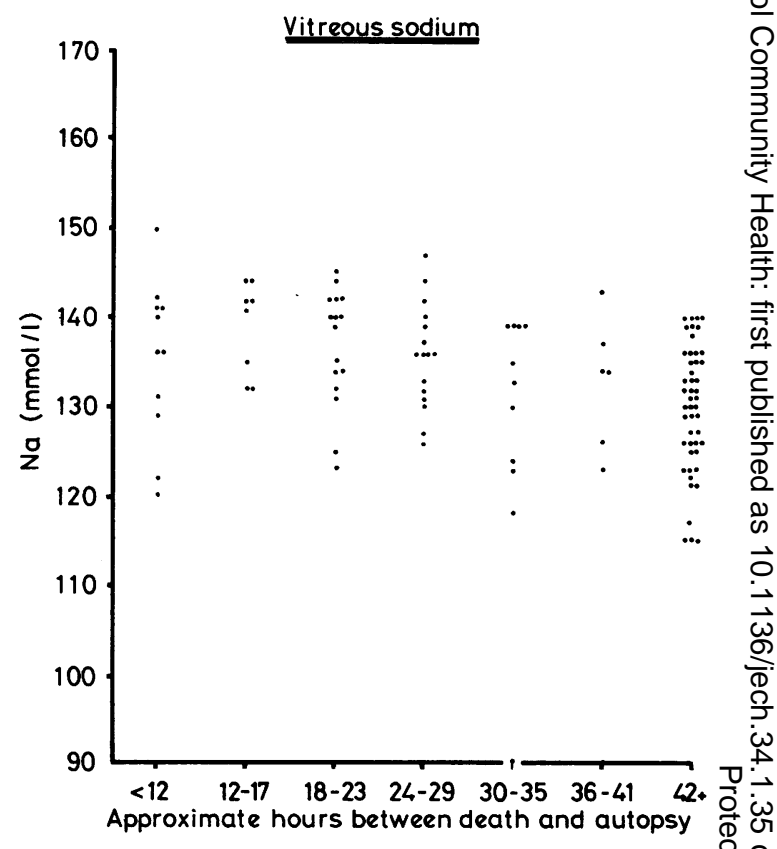

Fig. 2 Sodium concentration in the vitreous humour of 120 SIDS cases related to the interval between death and post-mortem dissection.

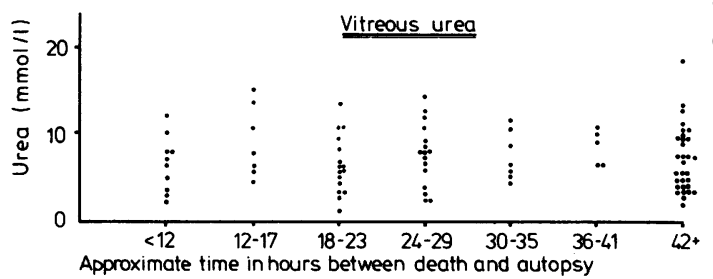

Fig. 3 Urea concentration in the vitreous humour of 90 SIDS cases related to the interval between death and post-mortem dissection.

As anticipated, ${ }^{12}{ }^{13}$ there is a statistically significant rise in vitreous potassium after death (Kendall's rank correlation coefficient $0.51 ; \mathrm{P}<0.001)$. There are two results in Fig. 1 which can be regarded as definitely hypokalaemic but, by and large, the extent and variation of the post-mortem rise are such as to render the analysis useless as an indicator of the aetiology of death and, incidentally, as an accurate measure of the post-mortem interval. ${ }^{12}$

Conversely, there is evidence of a decrease in vitreous sodium concentration during the post-mortem period (Kendall's rank correlation coefficient $-0.26 ; P<0.001)$. This confirms the findings of Swift, Worthy and Emery. ${ }^{14}$ The fall is of little concern in the interpretation of results. Any 
marginal effect it might have on the diagnosis of hypernatraemia would be to cause one to err on the side of conservatism. The diagram indicates three cases as being potentially significantly hypernatraemic and two as hyponatraemic.

No significant variation of urea levels related to time after death is demonstrated (correlation coefficient $0 \cdot 04$ ). Taking the upper limit of normal as $10 \mathrm{mmol} / \mathrm{l},{ }^{15}$ many cases do, however, appear to be uraemic.

The comparative sodium and urea values are illustrated in Fig. 4. The consistently normal or subnormal values discovered in breast-fed infants contrast markedly with the concentrations found in those who were bottle-fed. Twenty out of 75 bottle-fed cases in which both values were available had vitreous urea concentrations in excess of $10 \mathrm{mmol} / \mathrm{l}$ and, of these, one was clearly hypernatraemic. The results support those of Andrews, ${ }^{6}$ who found cerebrospinal fluid urea levels raised in 52 out of 54 cot deaths but no instances of a raised CSF sodium. There is no statistically significant biochemical distinction to be drawn between cases arising in the City of Edinburgh and those from elsewhere.

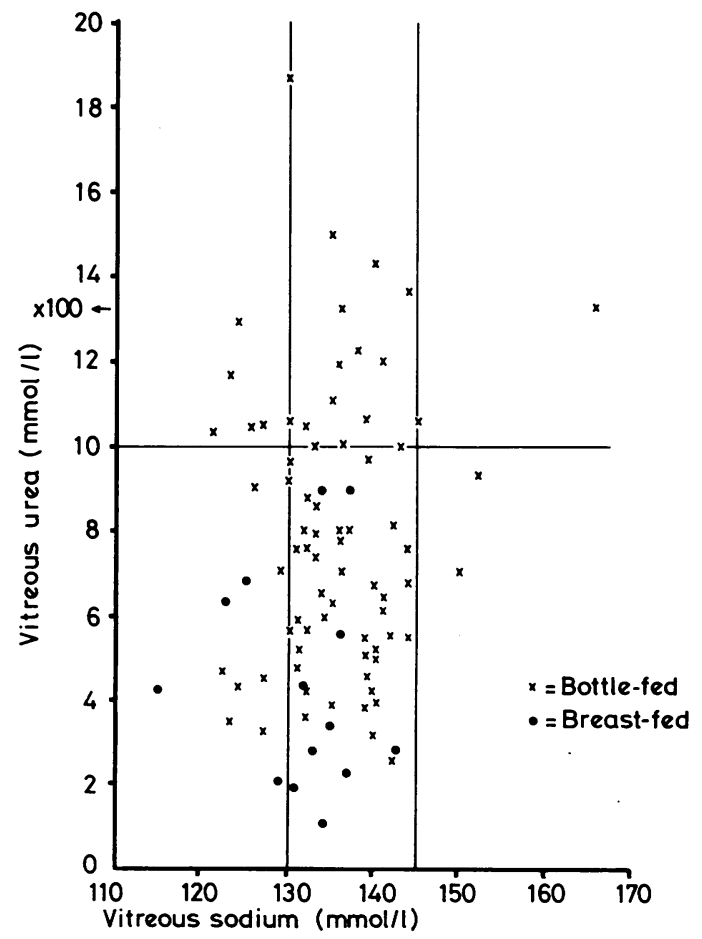

Fig. 4 Relationship between vitreous concentrations of sodium and urea in 89 SIDS cases.
SOCIAL STATUS

The social status of our cases is shown in Table 1 . There is a significant excess of infants born to parents in Social Classes IV and V $\left(\chi^{2}=30 \cdot 2,4 \mathrm{df}\right.$ $P<0.001)$; the differences occur mainly in children aged more than 12 weeks (Table 2). There is, however, less variation through the social strata when cot deaths are looked at as a proportion of all infant deaths $\left(\chi^{2}=11 \cdot 6,4 \mathrm{df}, \mathrm{P}<0.05\right)$ (Table 3$)$.

Table 1 Rates of SIDS/1000 live births for each social class

\begin{tabular}{lll}
\hline Social class & No. of deaths & Rate \\
\hline I & 11 & 1.93 \\
II & 11 & 1.23 \\
III & 42 & 1.58 \\
IV & 28 & 3.59 \\
V & 16 & $5 \cdot 24$ \\
& & \\
Total & 108 & 2.07 \\
\hline
\end{tabular}

The estimated population at risk is calculated from the number of live births/ social class in the Lothian and Borders Health Board Area in 1976."

Table 2 Rates for SIDS deaths related to infants under and over 12 weeks old

\begin{tabular}{|c|c|c|c|c|}
\hline \multirow{2}{*}{$\begin{array}{l}\text { Social } \\
\text { Class }\end{array}$} & \multicolumn{2}{|c|}{ Deaths $<12$ weeks } & \multicolumn{2}{|c|}{ Deaths $\geqslant 12$ weeks } \\
\hline & No. & Rate & No. & Rate \\
\hline I & 5 & 0.875 & 6 & 1.05 \\
\hline II & 5 & 0.56 & 6 & 0.67 \\
\hline III & 14 & 0.53 & 28 & 1.05 \\
\hline IV & 8 & 1.03 & 20 & 2.57 \\
\hline v & 3 & 0.98 & 13 & $4 \cdot 26$ \\
\hline Total & 35 & 0.67 & 73 & 1.40 \\
\hline
\end{tabular}

Table 3 Rate of SIDS deaths/1000 infant deaths for each social class

\begin{tabular}{lll}
\hline Social class & $\begin{array}{l}\text { No. of } \\
\text { SIDS deaths }\end{array}$ & Rate \\
\hline I & 11 & $186 \cdot 44$ \\
II & 11 & $102 \cdot 80$ \\
III & 42 & $140 \cdot 47$ \\
IV & 28 & $277 \cdot 23$ \\
V & 16 & 186.05 \\
& & \\
Total & 108 & 165.64 \\
\hline
\end{tabular}

There is a very highly significant tendency for younger mothers to cluster in the lower socioeconomic groups while the reverse holds for older mothers (Table 4). It may be that this trend is greater than it appears to be, because social class was not recorded in a surprising proportion of the group aged under 20 . 
Table 4 Age of mother and social class in SIDS cases

\begin{tabular}{|c|c|c|c|c|c|}
\hline \multirow[b]{2}{*}{ Social Class } & \multicolumn{4}{|c|}{ Age groups (years) } & \multirow[b]{2}{*}{ All ages } \\
\hline & Under 20 & $20-25$ & $26-30$ & $31+$ & \\
\hline \multirow{7}{*}{$\begin{array}{l}\text { I } \\
\text { II } \\
\text { III } \\
\text { IV } \\
\text { V } \\
\text { Unclassified* }\end{array}$} & - & 1 & 3 & 7 & 11 \\
\hline & - & 2 & 6 & 2 & 10 \\
\hline & 2 & 23 & 12 & 4 & 41 \\
\hline & 8 & 17 & - & 1 & 26 \\
\hline & 6 & 9 & 1 & 1 & 17 \\
\hline & - & 6 & 2 & - & 8 \\
\hline & 16 & 58 & 24 & 15 & 113 \\
\hline $\begin{array}{l}\text { \% of SIDS cases } \\
\text { \% Edinburgh marriages by age (1973) }\end{array}$ & $\begin{array}{l}14 \\
24\end{array}$ & $\begin{array}{l}51 \\
43\end{array}$ & $\begin{array}{l}21 \\
16\end{array}$ & $\begin{array}{l}13 \\
17\end{array}$ & - \\
\hline
\end{tabular}

* The fathers of the unclassified cases were serving in HM Forces.

Table 5 shows the type of feed the babies were taking at the time of death compared with average Edinburgh habits as given by the major maternity units. The two sets of figures are, therefore, not strictly comparable - some of the infants who were being bottle-fed at the time of death may have started for a short time on the breast. Subject to this limitation, however, there is an indicated deficit of breast-fed infants in the SIDS group. When the feeding habits are related to social class (Table 6) a highly significant association is demonstrated between breast-feeding and social class $\left(\chi^{2}=36 \cdot 2\right.$, $4 \mathrm{df}, \mathrm{P}<0 \cdot 001)$. In fact, the social class pattern in the SIDS group appears to account for some of the differences in Table 5: when the feeding habits in this group are standardised to the social class distribution of the general population, the estimated percentage of bottle-fed babies is reduced to $76 \cdot 3 \%$. Feeding habits are also associated with maternal age (Table 7). Younger mothers are more likely to bottle-feed but this effect is no longer significant when the relationship between maternal age and social class is taken into consideration using a linear logistic analysis. $^{16}$

Table 5 Type of feeding at time of death

\begin{tabular}{lll}
\hline & $\% \operatorname{SIDS}(n=119)$ & Edinburgh habits \%* \\
\hline Bottle & 79 & 71 \\
Breast & 16 & 27 \\
Weaned & 5 & 2 (mixed) \\
\hline
\end{tabular}

* Reported by major maternity units.

Table 6 Type of feeding at time of death and social class

\begin{tabular}{lllll}
\hline & \multicolumn{2}{l}{$\%$ of social class } & \\
\cline { 2 - 4 } Social Class & Bottle & Breast & Weaned & No. \\
\hline I and II & 35 & 60 & 5 & 20 \\
III & $72 \cdot 5$ & $17 \cdot 5$ & 10 & 40 \\
IV and V & 98 & - & 2 & 41 \\
Unclassified & 100 & - & - & 8 \\
\hline
\end{tabular}

Table 7 Feeding and maternal age

\begin{tabular}{lllll}
\hline \multirow{4}{*}{$\begin{array}{l}\text { Age group } \\
\text { (years) }\end{array}$} & \multicolumn{2}{l}{$\%$ of age group } & \\
\cline { 2 - 4 } & Bottle & Breast & Weaned & No. \\
\hline Under 20 & 94 & 0 & 6 & 18 \\
$20-25$ & 88 & 10 & 2 & 58 \\
$26-30$ & 61 & 39 & 0 & 23 \\
$31+$ & 53 & 47 & 0 & 15 \\
\hline
\end{tabular}

Tables 8 and 9 relate the biochemical findings in $\vec{p}$ the vitreous humour to the social status of the parents. There is no significant trend towardso abnormalities in the vitreous sodium level with lower socioeconomic grouping. Conversely, there is of definite tendency for uraemia to be associated with lower social status but there is no longer a significan class difference when the effect of bottle-feeding is taken into account (multiple regression of urea level on other variables). There is an apparent tendency for uraemia to be associated with infants of young mothers (Table 10); this is, again, explicable on the basis of feeding habits.

Table 8 Vitreous sodium and social class of bottle-fed SIDS cases $(n=89)$

\begin{tabular}{lccc}
\hline & \multicolumn{3}{l}{ Sodium $(\mathrm{mmol} / \mathrm{l})$} \\
\cline { 2 - 4 } Social Class & Below 130 & $130-145$ & $146+$ \\
\hline I and II & - & 7 & - \\
III & 9 & 24 & 1 \\
IV and V & 16 & 23 & 3 \\
Unclassified & 1 & 5 & - \\
\hline
\end{tabular}

Table 9 Vitreous urea and social class of SIDS cases $(n=67)$

\begin{tabular}{lcll}
\hline $\begin{array}{l}\text { Social } \\
\text { Class }\end{array}$ & $\begin{array}{l}\text { Urea } 10 \mathrm{mmol} / \mathrm{l} \\
\text { and under }\end{array}$ & $\begin{array}{l}\text { Urea over } \\
10 \mathrm{mmol} / \mathrm{l}\end{array}$ & $\begin{array}{l}\text { \% over } \\
10 \mathrm{mmol} / \mathrm{l}\end{array}$ \\
\hline I and II & 7 & - & - \\
III & 21 & 6 & 22 \\
IV and V & 15 & 12 & 44 \\
Unclassified & 6 & - & - \\
\hline
\end{tabular}


Table 10 Maternal age and infant vitreous urea: bottle fed infants

\begin{tabular}{|c|c|c|c|c|c|}
\hline \multirow{2}{*}{$\begin{array}{l}\% \text { in age } \\
\text { group }\end{array}$} & \multirow{2}{*}{$\begin{array}{l}\text { Maternal } \\
\text { age groups } \\
\text { (years) }\end{array}$} & \multirow{2}{*}{$\begin{array}{l}\text { Urea } 10 \mathrm{mmol} / \mathrm{l} \\
\text { and under }\end{array}$} & \multicolumn{2}{|c|}{ Urea over $10 \mathrm{mmol} / \mathrm{l}$} & \multirow{2}{*}{$\begin{array}{l}\text { Age of Edinburgh } \\
\text { women at marriage } \\
\text { \% }\end{array}$} \\
\hline & & & No. & $\%$ & \\
\hline 17 & Under 20 & 8 & 4 & 33 & 24 \\
\hline 53 & $20-25$ & 24 & 14 & 36 & 43 \\
\hline 19 & $26-30$ & 12 & 2 & 14 & 16 \\
\hline 11 & $31+$ & 8 & 0 & 0 & 17 \\
\hline
\end{tabular}

Since maternal age, social class, and number of previous children in the family are interrelated, both in the SIDS group and in the general population, a comparison with that population was carried out using a log-linear analysis. ${ }^{16}$ The distributions of both maternal age $\left(\chi^{2}=24.99,3 \mathrm{df}: \mathrm{P}<0.001\right)$ and number of previous children $\left(\chi^{2}=20.59,2 \mathrm{df}\right.$ : $P<0.001)$ differed significantly in the SIDS group when the social class differences were accounted for. Table 11 shows the SIDS mothers were younger than expected, and Table 12 shows that SIDS is more likely to occur with second children and less likely with first children; there is a comparatively small excess of cases with three or more children in the family. In this respect our results correspond most closely to those of Kraus, Steele, Thompson and de Grosbois $^{17}$ from Ontario.

Table 11 Maternal age distribution of SIDS cases

\begin{tabular}{lllll}
\hline \multicolumn{5}{c}{ Maternal age } \\
\cline { 2 - 5 } & $<20$ & $20-24$ & $25-29$ & $\geqslant 30$ \\
\hline SIDS & 15 & 49 & 23 & 14 \\
Expected & 8.88 & 33.11 & 38.72 & 20.27 \\
\hline
\end{tabular}

Expected frequencies are calculated from the general population ${ }^{25}$ corrected for social class and number of previous children.

Table 12 Number of previous children in families of SIDS cases

\begin{tabular}{llll}
\hline & \multicolumn{2}{l}{ No. of previous children } \\
\cline { 2 - 4 } & None & One & $\begin{array}{l}\text { More } \\
\text { than one }\end{array}$ \\
\hline SIDS & 28 & 53 & 20 \\
Expected & 48.11 & 36.49 & 16.40
\end{tabular}

Expected frequencies are calculated from the general population corrected for social class and maternal age.

The same analysis can also be used to test whether the trend in the incidence of SIDS across the social classes can be explained by the maternal age and birth order effects; it appears that this is largely true. Although the social class effect is still significant $\left(\chi^{2}=22 \cdot 80,4 \mathrm{df}, \mathrm{P}<0 \cdot 001\right)$, the effect is no longer simply that the risk increases with lower class. The corrected data (Table 13) suggest that, for given maternal age and birth order, those in Social Classes I, IV, and V are at greater risk than those in Social Classes II and III.

Table 13 Social class distribution of SIDS cases

\begin{tabular}{|c|c|c|c|c|c|}
\hline & \multicolumn{5}{|c|}{ Social Class } \\
\hline & $I$ & II & III & $I V$ & $\boldsymbol{V}$ \\
\hline $\begin{array}{l}\text { SIDS } \\
\text { Expected }\end{array}$ & $\begin{array}{l}11 \\
5.92\end{array}$ & $\begin{array}{l}10 \\
12 \cdot 56\end{array}$ & $\begin{array}{l}40 \\
54 \cdot 17\end{array}$ & $\begin{array}{l}25 \\
17 \cdot 33\end{array}$ & $\begin{array}{l}15 \\
11 \cdot 00\end{array}$ \\
\hline
\end{tabular}

Expected frequencies are calculated from the general population corrected for maternal age and birth order. Differences from Table 1 are due to missing values for these variables.

\section{Discussion}

The results of this investigation add little to the understanding of the cause of sudden infant deaths but give indications of the circumstances in which such deaths are likely to occur.

There is no evidence that severe electrolytic disturbance is a common cause or concomitant of the condition. Two cases may have been hypokalaemic. Both were rather old: one was aged 22 weeks and the other 28 weeks at death. Escherichia coli type 0126 was isolated from the intestine of the former while the latter showed some lymphocytic infiltration of the kidneys just compatible with a low-grade, presumably quiescent pyelonephritis; in addition, a single focus of lymphocytic infiltration of the myocardium was discovered. It is therefore possible that both these cases would have been excluded from many series of sudden unexpected infant death although both had a classic history.

Hyponatraemia was described as a significant abnormality by Sturner and Dempsey ${ }^{18}$ but, again, there are only two potential cases in our series. One showed some degree of glomerular sclerosis together with severe pulmonary oedema, both of which have been described in SIDS by Herbert and Andrews. ${ }^{19}$ No abnormality was discovered in the other case.

There were only three instances of hypernatraemia, compared with seven out of 40 cases reported by Emery et al. ${ }^{15}$ One of the two cases with a normal vitreous urea was atypical in being a rare 
instance of observed cot death in whom resuscitation in hospital was attempted. The other was noted at post-mortem dissection as appearing undernourished and dehydrated. The necropsy protocol of our only hypernatraemic and uraemic infant specifically notes that the infant was well nourished and cared for. The brain showed hypoxic changes in the cerebral hemispheres which were very similar to those ascribed to hypernatraemia by Macaulay and Watson. ${ }^{20}$

By contrast, we have confirmed the common occurrence of a low-grade uraemia in SIDS. Twenty of our cases exhibited a vitreous urea value of more than $10 \mathrm{mmol} / \mathrm{l}$ but there were no cases of uraemia in infants who were breast-fed at the time of death.

In only one infant was the vitreous urea $(18.6 \mathrm{mmol} / \mathrm{l})$ sufficiently high to suggest an association with the cause of death. The child was, however, well nourished and nothing was discovered which contradicted a pathological diagnosis of SIDS; the post-mortem was delayed for three days after death. Nevertheless, the total number of mildly uraemic infants is sufficient for the condition to be considered a common accompaniment of SIDS. Herbert and Andrews ${ }^{19}$ regarded it as invariable although they set their normal range far lower than we have done. Analysis of our cases indicates that an elevated urea concentration in the vitreous humour relates most strongly to bottle-feeding, and although less dramatic than those of Emery et al. ${ }^{15}$ our results support theirs. They demonstrated three cases with urea in excess of $10 \mathrm{mmol} / 1(60 \mathrm{mg} / 100 \mathrm{ml})$ and sodium levels higher than $150 \mathrm{mmol} / \mathrm{l}$ out of 40 infants studied; it has been suggested that hypernatraemic uraemia is possibly due to the frequent inaccuracies encountered in the reconstitution of milk feeds. ${ }^{5}$

The widely reported relationship between low social status and SIDS was confirmed although, in common with Fedrick, ${ }^{3}$ this was found to be mainly applicable to older children, aged more than 12 weeks. Further analysis of our cases shows, however, a strong association between lower social status and bottle-feeding and, because of this, there is a significant correlation between uraemia in the infant and social class of the mother. Similarly, there is a significant association between lower social class and the youth of mothers and, through the medium of bottle-feeding, between uraemic infants and young mothers.

In summary, our results show a close interrelationship between, on the one hand, a high incidence of SIDS and, on the other, young motherhood, low social status, bottle-feeding, and mildly uraemic infants. These factors depend upon each other and none appear to be of primary, independent significance. The findings are not entirely new and correspond closely to those obtained by Fedrick ${ }^{3}$ in central England and by Froggatt $e t$ al. ${ }^{1}$ in Northern Ireland. This is the first study of SIDS to come from Scotland and the conclusion is drawn that the milieu of SIDS is similar throughout the United Kingdom. The authors quoted and others (for example, Bergman et al. ${ }^{2}$ ) have extrapolated the epidemiological findings as indicating an infective aetiology. If this were so, SIDS would be expected to be most common in large families, and this has been reported. ${ }^{3}$ The relatively small excess of cases with more than one previous child in the family in our series does not, however, support the hypothesis that cross-infection due to overcrowding is a probable cause of cot deaths.

Objectively, the Edinburgh series seems to focus attention on a group of women who are likely to be least able to cope with the difficulties of motherhood. In England the same views have been expressed. ${ }^{21} 22$ The importance particularly attached to bottle-feeding can probably be reduced to being no more than a reflection of such a state. The incidence of SIDS cannot, however, be related simply to lowern social class and our data tend to show that factors such as maternal age and parity may be more important than social status per se.

Our home visitor found no subjective evidence of what Steele ${ }^{23}$ has described as the possibility of unwitting deprivation in some cases'. In additiono there is an apparently anomalous association of SIDSand parents in Social Class I. These considerations do not necessarily contradict a theory of 'mothering problems'. Much emphasis has recently been laid on the early recognition and skilled observation of at-risk infants with only minimal symptoms of disease $^{824}$; it could well be that the most devoted mothers are less likely to call the doctor in such circumstances. It remains true, however, that no single theory about the aetiology of SIDS will adequately account for all cases.

We thank Dr. A. D. Bain and Dr. I. I. Smith, both of the Royal Hospital for Sick Children, Edinburgh; Miss J. Darling and the late Dr. J. D. Crombie; and Mr. A. J. MacLeod, Medical Computing and Statistics Unit. We also thank the Procurator Fiscal, Mr. E. G. Smith, for permission to publish these data.

The study project was initially supported by a grant from the Foundation for the Study of Infant Death and, subsequently, by a grant from the Scottish Home and Health Department.

Reprints from Professor J. K. Mason, Department of Forensic Medicine, University of Edinburgh, Medical School, Teviot Place, Edinburgh EH8 9AG. 


\section{References}

${ }^{1}$ Froggatt P, Lynas MA, MacKenzie G. Epidemiology of sudden unexpected death in infants ('cot death') in Northern Ireland. Br J Prev Soc Med 1971; 25: 119-34.

${ }^{2}$ Bergman AB, Ray CG, Pomeroy MA, Wahl PW, Beckwith JB. Studies of the sudden infant death syndrome in King County, Washington - III Epidemiology. Pediatrics 1972; 49: 860-70.

${ }^{3}$ Fedrick J. Sudden unexpected deaths in infants in the Oxford Record Linkage Area: the mother. Br J Prev Soc Med 1974; 28: 93-7.

4 Cameron JM, Watson E. Sudden death in infancy in inner north London. J Pathol 1975;117: 55-61.

${ }^{5}$ Emery JL, Carpenter AG. Clinical aspects of the Sheffield prospective study of children at possibly increased risk. In: Robinson RR, ed. SIDS 1974. Canada: The Canadian Foundation for the Study of Infant Deaths, 1974: 97-106.

${ }^{6}$ Andrews PS. Cot deaths and malnutrition: the role of dehydration. Med Sci Law 1975; 15: 47-50.

${ }^{7}$ McWeeny PM, Emery JL. Unexpected post neonatal deaths (cot deaths) due to recognisable disease. Arch Dis Child 1975; 50: 191-6.

${ }^{8}$ Watson $E$. The inner north London study of sudden infant death and its relevance to the community services. Med Sci Law 1978; 18: 271-7.

'Adelson L, Kinney ER. Sudden and unexpected death in infancy and childhood. Pediatrics 1956; 17: 663-99.

${ }^{10}$ Beckwith JB. Sudden infant death syndrome. In: Bergman AB, Beckwith JB, Ray GC, eds. Proceedings of the Second International Conference on Causes of Sudden Death in Infants. Seattle: University of Washington Press, 1970: 18.

11 Carpenter RG, Emery JL. The identification and follow-up of high risk infants. In: Robinson RR, ed. SIDS 1974. Canada: The Canadian Foundation for the Study of Infant Deaths, 1974: 91-6.

${ }^{12}$ Sturner WQ, Gantner GE. The post-mortem interval: a study of potassium in the vitreous humor. Am J Clin Pathol 1964; 42: 137-44.
${ }^{13}$ Coe JI. Post mortem chemistries on human vitreous humor. Am J Clin Pathol 1969; 51: 741-50.

${ }^{14}$ Swift PGF, Worthy E, Emery JL. Biochemical state of the vitreous humour of infants at necropsy. Arch Dis Child 1974; 49: 680-5.

${ }^{15}$ Emery JL, Swift PGF, Worthy E. Hypernatraemia and uraemia in unexpected death in infancy. Arch Dis Child 1974; 49: 686-92.

${ }^{16}$ Everitt BS. The analysis of contingency tables. London: Chapman and Hall, 1977.

${ }^{17}$ Kraus AS, Steele R, Thompson MG, de Grosbois P. Further epidemiologic observations on sudden unexpected deaths in infancy in Ontario. Can J Public Health 1971; 62: 210-19.

${ }^{18}$ Sturner WQ, Dempsey JL. Sudden infant death: chemical analysis of vitreous humor. J Forensic Sci 1973; 18: 12-19.

${ }^{19}$ Herbert A, Andrews PS. The pathology of cot deaths. $J$ Pathol 1979; 128: 39-48.

${ }^{20}$ Macaulay D, Watson M. Hypernatraemia in infants as a cause of brain damage. Arch Dis Child 1967; 42: 485-91.

${ }^{21}$ Protestos CD, Carpenter RG, McWeeny PM, Emery JL. Obstetric and perinatal histories of children who died unexpectedly (cot deaths). Arch Dis Child 1973; 48: 835-41.

${ }^{22}$ Watson E. Two clustered cases of 'cot death' with idential physical and social pathology. Med Sci Law 1977; 17: 183-6.

${ }^{23}$ Steele $R$. The epidemiology of SIDS in Ontario. In: Robinson RR, ed. SIDS 1974. Canada: The Canadian Foundation for the Study of Infant Deaths, 1974: 85-9.

${ }^{24}$ Carpenter RG, Emery JL. Final results of study of infants at risk of sudden death in infancy. Nature 1977; 268: 724-5.

${ }^{25}$ Registrar General for Scotland. Annual Report, 1976. Edinburgh: HMSO, 1977. 